\title{
Reflection in Practice as Source of Values: The Cross-cultural Creation of a Health-care Ethic in Post-Apartheid South Africa
}

\author{
Augustine Shutte \\ lara.davison@uct.ac.za
}

\begin{abstract}
As a starting-point, in his well-known definition of a 'practice', Alasdair MacIntyre argues that the 'reflection' involved in 'practice', is best understood as a dialogue between different partners, whether individuals or groups. Such reflection, aimed as it is at the achievement of excellence in the practice concerned, can (if pursued with rigour and commitment), uncover values embedded in the practice which, however limited the practice (rugby, gardening), have a wider, even universal, scope. When the partners in dialogue have general recognition of one another (religions, countries, professional bodies, political parties), these values can provide materials for a Global Ethic (Parliament of the World's Religions), that is constructed from the bottom up (the Oregon Plan), rather than by some public authority (the United Nations). This article provides grounds for this view by examining the practice of healthcare in post-apartheid South Africa, and the co-reflection of scientific healthcare professionals and traditional healers, that are part of constructing a new model for health-care that better serves the needs of all South Africans. This dialogue may uncover values whose scope is wider than that of health-care and which could provide a really humane foundation for a society containing different cultures.
\end{abstract}

Keywords: practice, Alisdair MacIntyre, reflection, values, culture/s, ethic, health-care professionals, traditional healers 


\section{Introduction}

This article provides grounds for the view that a National Ethic, but, equally, a Global Ethic for health-care practice can be developed from the ground up, rather than from the top down. As a starting-point, in his well-known definition of a 'practice', Alasdair MacIntyre argues that the 'reflection' involved in 'practice', is best understood as a dialogue between different partners, whether individuals or groups. Such reflection, aimed as it is at the achievement of excellence in the practice concerned, can (if pursued with rigour and commitment), uncover values embedded in the practice which, however limited the practice (rugby, gardening), have a wider, even universal, scope. When the partners in dialogue have general recognition of one another (religions, countries, professional bodies, political parties), these values can provide materials for a Global Ethic (Parliament of the World's Religions), that is constructed from the bottom up (the Oregon Plan), rather than by some public authority (the United Nations). This is the main focus of this article. By examining the practice of health-care in post-apartheid South Africa, and the co-reflection, or dialogue of scientific health-care professionals and traditional healers, that are part of constructing a new model for health-care that better serves the needs of all South Africans, this article outlines the possibilities and dynamics of such interaction. It may uncover values whose scope is wider than that of health-care and which could provide a really humane foundation for a society containing different cultures.

\section{'Practice': The Normative and Reflective/ Dialogal}

I am sure you are all familiar with Alasdair MacIntyre's well-known definition of those 'large-scale complex worthwhile activities' we call practices. Wellknown or not, it is much too complex to be remembered. So here it is, in what a mutual friend of ours, Herbert McCabe, referred to as 'one large-scale complex worthwhile sentence':

By 'practice' I am going to mean a coherent and complex form of socially established co-operative human activity through which goods internal to that activity are realised in the course of trying to achieve those standards of excellence which are appropriate to and partially definitive of that form of activity, with the result that human powers to 
achieve excellence, and human conceptions of the ends and goods involved are systematically extended (1985: 175).

McCabe takes as an example of a practice the making and maintaining of a family. (McCabe, incidentally, although not as well-known as such figures as MacIntyre and Charles Taylor, was one of the most powerful influences behind the recent rebirth of Aristotelianism in philosophy. MacIntyre in particular has been deeply influenced by him.) His description of this practice is such a good illustration of MacIntyre's definition that I am going to share it with you:

Having and maintaining a family as an activity of parents is complex and coherent in the sense that it is a distinguishable form of activity with its own pattern to it, and also of course co-operative. And the cooperation is a matter not only of relations between the two parents and their children but also many other agents and agencies essential to family life, like grocers, schools, clinics, and so on. In maintaining a family we are concerned with goods internal to the activity. That is we do not maintain a family in order to realise some good which might have been realised in some other way. In this sense running a family is 'for its own sake'. These goods are realised in the course of trying to achieve certain standards of excellence that belong to running families - making sure that the children are healthy, adequately fed and clothed, educated and so on, that the family 'forms a coherent unity in friendship', that it plays its part in appropriate social activities hospitality and all the rest. With the result that human powers to achieve these excellences are systematically extended; so that not only do these parents get better at the job, but throughout a section of history the activity of maintaining a family becomes better understood and practised. And finally throughout such a personal life and such a history the idea of what a family is and what the goods are that belong to it is gradually revised and extended. To put it simply, by trying in practice to be good parents we (individually and as a society) deepen our notion of what it is to be a parent (1980: 72).

There are two things that this example of a practice brings out very clearly: its normative nature; and the fact that a reflective element is intrinsic to it. These 
two things are of course closely connected but let me examine them one by one.

\section{The Normative Dimension}

In saying that practices have a normative dimension one is really saying that human life as such has a normative dimension to it. This is certainly what MacIntyre is concerned to show in After Virtue. Facts and values are inseparable when it is humanity we are dealing with. The famous impossibility of deriving an 'ought' from an 'is' turns out to be possible after all. If the 'is' is a human 'is', the 'ought' is already there, 'built in', as it were to our human nature. Each of all the sciences is capable of taking humanity as its object of study. But humanity, as well as being a possible object of study is also, in the person of the scientist, the thinking, choosing subject who produces science, deliberates about its procedures and judges its methods. As knowing subjects we cannot but engage in normative activities of a theoretical kind. As choosing agents we cannot but engage in normative activities of a practical kind. Whether in our thinking or in our choosing there is no avoiding our normative nature. We are condemned to value!

It is the fact that all human practices have a built-in normative dimension to them that both provides a space and creates a demand for reflection. For if it is the case that a practice is something that can be well or badly practised there is a built-in pressure in it towards excellence. Think of football, think of cooking, think of anything we do. Embedded in the practice, sometimes hidden, sometimes evident, is its natural standard, waiting to be uncovered, formulated, applied. Thus emerges reflection, not imported, not superimposed, but engaged in, intrinsic to, partially definitive of, the practice.

\section{The Reflective/ Dialogical Dimension}

The reflection that is an intrinsic aspect of human practices is thus an essentially critical activity. It is of course concerned to understand the practice in question. But the insight it seeks, it seeks in order to enable it to evaluate the performance according to the built-in standard that has been uncovered. Reflection in practice is thus essentially productive of values. This seems to 
me undeniable and is explained by the notion of human beings as subjects and agents that I have just emphasised. What is perhaps less evident is that such reflection has a built-in dialogal element to it.

This is clearly the case in McCabe's example, where both husband and wife are the subjects and agents of making and maintaining a family. But what of a one parent family, or a medical professional? Even there it seems to me a dialogal element is present in reflection on the practice. Since such reflection is always critical, the mental acts involve considerations both for and against some particular detail of the practice concerned. Should one tell the patient the full scope of the diagnosis? Or not? Should one tell them now or when they are feeling better? The either/or structure of one's practical deliberations has a dialogal character to it. One considers reasons for and against, pro's and con's. The very act of examining one's usual practice in a critical way implies that one has taken up a stance over against it. I do not think it is irrelevant that a literary genius such as Plato chose the dialogue form for his philosophical writing. And this was continued, though in a more formalised way in the scholastic disputation of the Middle Ages.

In spite of the fact that a dialogal aspect is always present in critical reflection it is more evident and, I want to claim, more significant when actual different partners are involved. As the old saying goes, 'two heads are better than one'. The truth in this is not merely that two guesses give you double the chance of being right, but rather that an intersubjective agreement is more likely to be objective, avoiding the preconceptions and biases of a single individual. But there is more to the importance of dialogue than this. One can get a hold on what that is by recognising that however trivial (within limits) the practice under consideration is, the values uncovered by reflection, and the effect of the reflection on the reflector, can be very far-reaching indeed, with the whole of human life as their scope. Consider a practice such as football. A particular period of European competition saw a Dutch team, Ajax Amsterdam, evolve a new style of play: 'total football'. This made new demands not only on the skills but even on the character of the members of the team. For instance forwards had to be prepared to play as backs, and vice versa. This required courage and a high degree of selflessness. Only certain players were able to fit into such a team. Few would deny that qualities such as these, necessary for excellence on the football field, are equally important for the whole of a persons's life. So sport is often used in schooling as a source of moral education. 
Now if this is true of something like sport, how much more so is it true of such essential practices as making and maintaining a family, health care, the police service, government or religion. In practices like these it is quite clear that the values involved have to do with human life as a whole. In these practices it is much clearer than in the case of sport that to succeed in the practice is to succeed as a human being. Or, to put it the other way round, that in order to be good at things like this you need to be a good person as well. The values involved in being a good policeman have a depth and scope that affects everything you are.

What seems to me to be the case is that the values we can discover by reflection in practice are potentially universalisable not because of the nature of the practice as such but because the practice is a particular realisation of human beings as subjects and agents. And as subjects and agents we human beings are virtually unlimited in the different ways in which we are able to realise those values that are universal because fundamental to all the practices essential to a worthwhile and fulfilling human life. It is this apparent lack of limitation that establishes the necessity of dialogue between different partners in the reflective search for values in the practices in which we are involved. A single source of reflection is not capable of revealing the richness of possibilities inherent in the practice. This is as true of football as it is of healthcare. Every practice because it is an expression of our humanity is open-ended, capable of an indefinite variety of expressions, unlimited development. Our existence is historical, continuously developing, and so our reflection can never be over if our practices are to retain their integrity and health.

\section{The Practice of Health-care in Post-apartheid South Africa}

We have been swimming in deep waters. I want now to give my reflections more grounding by exploring a particular practice that I am familiar with, namely the practice of health-care in post-apartheid South Africa. What I have said so far has been said in terms of individuals as partners in dialogue. I think one can apply the same argument to groups, organisations, societies, cultures. This is what I propose to do.

It is important to remember that South Africa is the most European country in Africa, including Mediterranean Africa. I use the term European rather than Western since what I am referring to is the kind of culture and 
society that developed in Europe during the modern period and has since spread across the world. The backbone of this colossus is the science that developed in Europe at this time and the technology it made possible. It is this science and technology that define the notion of development in our time. South Africa can be said to be the most developed country in Africa. On the other hand, because of apartheid, South Africa is also a country that contains both the Third World and the First World, the North and South, the developed and the under developed, within itself. It is in this way a microcosm of the contemporary global community. For that very reason it is a suitable place to perform a crucial experiment in finding a way of bridging the widening gap in our globalising world between those who are and those who are not 'developed'.

What makes South Africa unique in post-colonial Africa is, first of all, that here the colonists stayed. And then there was apartheid. The result of these two factors was both the powerful presence of Europe and a sharp separation between Europe and Africa. It was a contradiction that could not continue to exist, but also one that produced a heightened consciousness of identity and difference. Later in this paper I will have something to say about the extraordinary ending of apartheid. Here I only want to point out that our present project of 'nation-building' in South Africa is a project of bringing together what apartheid forced apart. People and groups of people, of course, but also cultures and ways of living, ideas, values. In every sphere of life - gender relations, sex and family, education, work, government, religion - the struggle continues to develop connections. Beyond political reconciliation we are hoping for a genuine marriage - what Leopold Senghor called 'cultural miscegenation' - of Africa and Europe that will be a real enhancement of our multicultural humanity. Archbishop Desmond Tutu's playful but beautiful notion of a 'rainbow nation' is an apt symbol of our society in which the same light of our humanity shows itself in so many different colourful ways. The project of 'nation-building', if it is to be authentic, must involve the search, within our different cultures, for values that, because they grow from our common humanity, we all can recognise and which can unite us in a humane common life.

I propose now to take as an example of this search, the sphere of health-care in South Africa, and give you some concrete cases of reflection in practice that is also the co-reflection of different partners in dialogue, and which could lead to the discovery of values that can be shared. 


\section{The Two Main Traditions of Health-care in South Africa}

There are two main traditions of health-care in South Africa, modern European medicine and traditional African medicine. European medicine in South Africa has a predominantly American character. It is scientific and technical. The medical establishment is doctor and male-dominated. Health-care focuses mainly on the curing of acute conditions. It has clear and limited goals with increasing specialisation. Ethical interest focuses almost exclusively on the extraordinary, the moral dilemmas created by technological advances in medicine. Its aims and character are also affected by its concern with rules and law, both professional and legal. In a market economy the practice of medicine has been profoundly influenced by the individualistic and materialist ethos of its liberal/ capitalist setting and its commercial aims and methods. The huge omnicompetent hospital is its typical embodiment and most powerful symbol.

Traditional African medicine is very different. The most profound difference can be seen in the following statement of a Zulu medical practitioner in dialogue with a European psychiatrist:

Whites have failed to see that in Africa a human being is a single entity, not divided up into various sections such as the physical body, the soul and the spirit. When a Zulu is sick it is the whole [person] that is sick ... (Buhrmann 1984: 32).

Commenting on this, the psychiatrist, Vera Buhrmann, writes,

Western medicine divides illness into the different categories of somatic, psychological and psychosomatic: the Black people do not: they say that 'when part of me is ill, the whole of me is ill', irrespective of what the illness is (1984: 26).

Unlike the germ theory of disease of scientific medicine, traditional African medicine distinguishes between natural and unnatural causes of disease. Natural causes refer to anything that can enter the body, either through one of its orifices or through the skin. Unnatural causes include psychological influences, evil deeds (of self or others), sorcery, the spirits of ancestors. Dealing with these involves a variety of methods from herbal remedies, changes of diet, dancing and drumming, to counselling and prayer. 
Since the ending of apartheid attempts to bring these different traditions of health-care together have been made at many different levels. At the level of the national government, the Portfolio Committee on Arts, Culture, Language, Science and Technology has launched an Indigenous Knowledge Systems (IKS) programme that intends to feed IKS into institutions of higher learning, science councils, government structures, and corporate entities in both the public and private sectors. A particular initiative of government in the field of health-care has been to convert the infamous Vlakplaas farm (which in the apartheid era had been the training school for spies, torturers and other 'security' personnel) into a national centre for healing and reconciliation. Here traditional healers and scientific medics practise side by side, referring patients to each other as they see fit.

Through the Human Sciences Research Council research into these indigenous knowledge systems is being sponsored. A colleague of mine at the University of Kwa-Zulu Natal is at present running a research project in IKS that focuses explicitly on the sphere of health-care. He writes that

The assumption that this would be fruitful was based not only on the fact that much of the indigenous knowledge that exists is to do with medicine, but that medicine and health could open up many other avenues of investigation. This in turn was based on the assumption that the world-view out of which IK emerges is an interconnected whole where boundaries between the material and the spiritual, the sacred and the secular, the individual and the community are blurred. It is precisely this interconnectedness of the whole of reality that so profoundly characterizes IK in general and medicine and healing in particular. It is therefore on the basis of the assumption that investigation into the topic of healing and medicine will potentially open up the entire field of IK that our project was launched. And in fact many other topics have indeed emerged. However they have emerged through the doorway opened to them by ideas, practices, traditions, and beliefs around the topic of medicine and healing (Balcomb 2005).

This project involves a large(18 strong) group of traditional healers, diviners, herbalists and religious practitioners, as well as academics from a variety of disciplines including medicine, anthropology, psychology, chemistry and religious studies. 
At my own University of Cape Town a group of academics from medical specialisations calling itself 'The Medical Research Council Traditional Medicines Research Group' has been meeting for some years with a similar group of traditional healers and herbalists. Together they have published the South African Primary Health Care Handbook (Felhaber 1999). The subtitle of this volume explains the character of the book: 'Combining Western and Traditional Practices'. It does just that. Beginning with theoretical sections on traditional and Western concepts of disease, diagnosis and treatment, it then covers in a practical way the full range of primary healthcare issues, combining the approaches of both traditional and scientific medical practice.

\section{Traditional and Scientific Medical Practice: Co-reflection in Practice}

\section{The Dialogue between the European and the African Traditions}

To give a deeper insight into what is involved in this co-reflection in practice of two different health-care traditions I want to look more closely at the experience of an individual who deliberately involved herself in a dialogue between the European and the African traditions as presently existing in South Africa. Her reflections are published in an extraordinary little book Living in Two Worlds (Buhrmann 1984). The subtitle explains the title: 'Communication between a White Healer and her Black Counterparts'.

We have already met the person involved, in the dialogue with a Zulu doctor I have quoted. Her name was (she has recently died) Vera Buhrmann. She was an academic at the University of Cape Town, a European-trained psychiatrist and a Jungian analyst. Through a student she was introduced to the Tiso school, a group of Xhosa amagqira (indigenous healers) who worked especially with patients suffering from psychological disorders. She became so interested in their work and their methods that she began to spend several weeks each year living with them in their remote country region and participating in their work.

As the patients were suffering from psychological disorders which, as a psychiatrist and analyst, were her special field, she was particularly interested in similarities and differences in the therapies involved. To give you an impression of this, here is her description of the therapeutic milieu: 
... from the beginning the patient is incorporated into the life and activities of the igqira's household. S/he is treated like a member of the family, with the privileges and responsibilities inherent in such a position. The chores allotted to [the patient] depend on his/ her state of health and ability to assume responsibility; these increase with progress. The nature of the patient's duties is naturally determined by the person's sex. The value and importance of work is stressed: 'Noone may be idle' is a dictum. There is constant interaction between the patient, members of the family and other patients and trainees, and on the whole the atmosphere is warm and friendly, with much talking and joking going on. Gradually the patient's sense of isolation, loneliness and being different decreases, and his/ her self-esteem and selfconfidence increase. Patients who are restless and violent are given sedation of some kind at night and even during the day.

Such an environment is humane and health-promoting. It has advantages over the hospitals and institutions which the West has to offer. The work with the animals, on the lands, in the gardens, around the homestead and in the homes, is occupational therapy which is natural and meaningful to the person and which s/he shares with the others, sick and healthy. The loneliness and feelings of isolation which are characteristics of all mental disturbances are therefore naturally dealt with in therapy from the outset. There is little that is strange, unknown or frightening; the patient is transferred from his/ her own home to another home, not a hospital; there are no language barriers, the same cultural ideas are shared, even the food is traditional. There is no culture-shock. S/he sees the 'doctor', the igqira, going about his/ her ordinary duties as head of the homestead, dressed in ordinary clothing, and s/he gets to know him/ her as an ordinary human being. If the igqira is a woman, she also performs her ordinary duties like any other woman who runs a home (1984:42).

As in orthodox psychoanalytic practice, where training also involves analysis, some of the igqira's 'patients' are also trainees. Vera Buhrmann was herself initially in this category though eventually she became a fully-fledged igqira.

We have neither time nor space to discuss the details of treatment of the Tiso school, but they involved herbal remedies and physical procedures 
together with dream analysis and ceremonies with dancing, as well as the kind of occupational therapy outlined above. In all of this, in the work on dreams as well as in the ceremonies, the role of 'the ancestors' is of supreme importance. Indeed, in Buhrmann's view it is in relation to the ancestors that the contents of the unconscious are revealed for the African patient.

\section{The Similarities and Differences of the Two Different Therapeutic Traditions}

What I want to focus on are the similarities and differences noted by Buhrmann of the two different therapeutic traditions, and then on her discernment of the effect the African practice had on her.

Buhrmann describes the world of Western medicine (and she is thinking particularly of psychotherapy) as 'primarily scientific, rational and ego-oriented', whereas 'the world of the Black healer and his/ her people ... is primarily intuitive, non-rational or oriented towards the inner world of symbols and images of the collective unconscious' (1984: 15). She quotes with approval Senghor's distinction between discursive and intuitive reason, applying the former to Western thinking and the latter to African. She acknowledges that she is writing for Western readers and so tends to stress what she feels Western medicine has to learn from its African counterpart rather than vice versa. She is critical of central aspects of Western culture and eager to communicate the strengths of the African.

There is considerable evidence in the Western world that our one-sided conscious ego attitudes need to be corrected. There is also evidence that unconscious forces are at work in a rather destructive way because we are deaf, blind and insensitive to the need of the unconscious to find expression. We all need to 'listen to the ancestors' and get to know and understand their wishes.

The African continent is in a somewhat similar dilemma: because of the extreme pressure on its Black inhabitants to develop a Western-orientated society, a Western type of ego-consciousness with Western goals and measures of achievement, they now also have difficulty listening to the ancestors, and even more important, understanding their messages. This leads to anxiety, confusion and a search for identity (1984: 100). 
Ultimately however, she recognises strengths and weaknesses in both and argues for a complementarity between them.

Western culture has the advantage - and it is an advantage not to be scorned - of having developed a relatively conscious and relatively logical goal-directed ego .... Our Black compatriots, especially those with whom I have worked, have the advantage of still living closer to the world of the unconscious, where symbols are still alive and vibrant and where archetypal images form a natural part of their daily existence and direct their behaviour in ways which sometimes seem irrational to us. Their ego-structure and functions are less goaldirected, except when they are gripped by an idea or an activity, when their ego-structure does become goal-directed and the energy which is released under such conditions seems inexhaustible (1984: 100-101).

The complementarity of these two cultures was not simply a theoretical one; it was realised in her own experience.

In my research into the rituals and ceremonies, intuition and feeling naturally took over and thinking was only applied when it came to talking or writing about my experiences and perceptions. My Black mentors therefore unwittingly sharpened my functions of intuition and feeling. They in turn said on more than one occasion: 'Working with you is a great help, you help me to think and see things deeper'. It therefore seems to me that our natural modes of functioning were complementary to each other, and that something more integrated and less one-sided emerged out of this co-operation (1984: 101-102).

\section{The Effects of Immersion in the Healing Practices of the Xhosa}

We come now to consider the effects Buhrmann's immersion in the healing practices of the Xhosa had on her. She lists the chief insights she gained from her experiences as follows:

- Acceptance of the fact that the rational and non-rational parts of the psyche are equally important in the totality of the human being. 
- The ancestor concept of the Xhosa, especially as it is conceived of and used by the Tiso school for the purposes of healing.

- The Xhosa attitude to dreams: that these are communications from the ancestors and may therefore not be ignored and that every effort must be made to understand the messages these dreams convey.

- The significance of the intlombe and xhentsa (ritual healing dances) during which body and spirit find expression and are united in a beautiful and meaningful way (1984: 17-18).

Although her immersion in traditional therapy had such a profound effect upon her, Vera Buhrmann retained her hold on scientific and Jungian medicine. The African insights did not displace but complemented her European education. The extent to which they did this, and the profound effect this merging of complementary influences had on her, is beautifully illustrated by the mutuality, the reciprocity, the near identity, that developed in the relationship between Vera and her Xhosa colleagues.

At the most fruitful encounters I felt that 'our animals were working together' and I was aware of the palpable but invisible presence of their ancestors. These occasions consisted of a genuine therapeutic relationship from which both parties derived benefit. Some of the benefits derived are obvious, some so subtle that they defy definition. As human beings we interacted with each other in a unique way and at unique levels - mostly at an intuitive, emotional and even archetypal level. My understanding of and sensitivity to symbolism as expressed in language and behaviour formed a bridge across which energy could flow in both directions. At times, I felt that similar archetypal experiences were stimulated, and each intuitively knew what was happening to the other (1984: 99).

What happened to Vera Buhrmann and Mongezi Tiso, and to the practice of psychotherapy in South Africa, is a good illustration of the critical and creative power of the co-reflection of different partners. And, in a healthy society this kind of co-operative critical reflection is part of the never ending conversation that is the cultural heart of a community. I, as a philosopher, want to take part in this conversation between European and African in South Africa, by extending the reflection more widely and more deeply. I begin in the sphere 
of health care but find there values that have a wider, deeper scope.

\section{The Ethos Inherent in the European and the African Practice of Health-care}

I begin where Buhrmann left off, by examining the different ethos inherent in each of the European and the African practice of health-care. I am conscious that I am writing for, and speaking to, a predominantly European audience. And although I am born and bred in South African I have inherited and been educated in a predominantly European culture. For both these reasons I am, and will be, more concerned to note the negative aspects of the European ethos in health-care and the positive ones in the African. There is however a more important reason for this: European culture is the dominant culture globally, and increasingly so. And nowhere more so than in the sphere of health-care. So it is only too easy to accept it as normative. I have however discovered in African culture something that Europe has either forgotten or lost and I am eager to bear witness to this. In the end though, all cultures contain both negative and positive elements and I will try to identify these fairly. My ultimate aim is to see whether it is possible to combine the best of both.

\section{The Ethos of European Health-care}

I have already commented on the ethos of European health-care. Here I will add to this a few remarks on health-care ethics itself in the presently dominant European tradition. As one would expect there is a strong connection between the actual ethos of a practice and ethical reflection on it.

Contemporary medical ethics in the European tradition is formed by two main ethical traditions, the utilitarian and the deontological. The most influential school of medical ethics, that of Georgetown, distinguishes four fundamental principles: autonomy, justice, beneficence and non-maleficence. The first two, rooted as they are in the deontological ethics of Kant, are expressions of the abstract rationality of the universalisability of the maxims of one's actions. The second, utilitarian, pair embody an instrumental view of rationality that is reduced in practice to a cost/benefit calculus. All four can be seen as no more than procedural rules for regulating the interests of interacting self-interested agents. Justice is reduced to mere equality of consideration, 
autonomy to freedom from interference. Beneficence and non-maleficence are merely cost-benefit calculations. Ethics of this kind is virtually, absurdly, value-free. There is no conception of what human fulfilment consists in, or what the connection between human goodness and good health-care ought to be. It has no concern for the actual quality of life that goes on in this sphere of society, but aims only to provide a set of rules that will enable autonomous self-interested agents, seeking a variety of heterogeneous goals, to interact with each other without conflict within a system set up by 'experts' and administered by 'managers'.

Clearly such a negative assessment is inadequate as a characterization of the whole tradition. I have nevertheless picked out elements which I believe are really there. They are not however the whole story. European medicine has achieved colossal success in the eradication of epidemics and in the treatment of acute conditions. The result of this success has been a shift in the focus of health-care to the management of more or less chronic conditions and to the final years of people's lives. From an ethical point of view however I consider the most significant achievement to be what I will call the patient-centred view of health-care. In a context of increased specialisation, health-care is inevitably a multi-disciplinary matter performed to a greater or less extent by a healthcare 'team'. The ethical insight I want to emphasize is that which sees the patient as the leader and director of this team.

This value-laden understanding of health-care is embodied in such notions as 'informed consent', 'confidentiality' and many others. Ultimately however all are rooted in the notion of autonomy I have already mentioned. Of the four Georgetown principles, autonomy is definitely the 'trump'. In the background of this reverence for patient autonomy is the history of modern European culture in general and philosophy in particular. The period that saw the rise of science and technology and secularisation also saw the development of the idea of individual freedom as both the most important fact about human nature and the most important value for human life. This insight finds beautiful expression in the following quotation from Pico della Mirandola's Oration on the Dignity of Man. God is speaking to Adam:

Neither a fixed abode nor a form that is yours alone nor any function peculiar to yourself have we given you Adam, to the end that according to your longing and according to your judgement you may have and possess what abode, what form, what functions you yourself shall 
desire. The nature of all other beings is limited and constrained within the bounds of laws prescribed by Us. You, constrained by no limits, in accordance with your own free will, in whose hand We have placed you, shall ordain for yourself the limits of your nature. We have set you at the world's centre that you may from there more easily observe whatever is in the world. We have made you neither of heaven nor of earth, neither mortal nor immortal, so that with freedom of choice and with honour, as though the maker and moulder of yourself, you may fashion yourself in whatever shape you shall prefer (Taylor 1989: 199200).

Since that time this notion of individual freedom as self-determination has become the foundation of all ethical thinking. Unfortunately it was given its classical formulation by Kant in starkly dualistic terms. According to him, as rational beings we are free from the determinisms of nature of which our bodies are, unfortunately, a part. This dualistic understanding of human nature has its counterpart in the realm of ethics. Here freedom is understood as a radical independence of, amounting to a separation from, others. Individuals are not an integral part of the community; the community is simply an aggregate of individuals. Dualism and atomism go hand in hand. In spite of this, freedom as an ethical notion is in my view a permanent and valuable contribution to ethical thought, but one that requires a more adequate formulation.

\section{The African Ethos of Ubuntu}

I turn now to a deeper reflection on the African ethical thinking that underlies the ethos of health-care practice in this tradition. The central and foundational African ethical notion is that of ubuntu, which means 'humanity' as a moral quality of a person or their behaviour. To understand the concept of ubuntu it is necessary to say something about the conception of human nature that underlies it. This conception is encapsulated in the saying that umuntu ngumuntu ngabantu - a human being is a human being through (other) human beings. This entails, in the first place, that my humanity is both a gift and an achievement. It is not present in the beginning but is progressively realised through my relations with others - or not. Humanity is something which can fail to be developed - hence the normative force of the concept of ubuntu. It 
can readily be seen that the notion of ubuntu is very close to that of health, where health is understood as a quality of the whole person - physical, psychological and spiritual aspects all taken together. In fact that is precisely what we have seen in Buhrmann's account of traditional healing. Health-care, in the African tradition, is seen as but one aspect of that comprehensive and life-long interpersonal interaction that engenders the exercise, development and flourishing of humanity in individuals. In the sphere of health-care the power for growth in humanity through interpersonal relations is focussed in specific ways - in herbal treatment, surgery, ritual dances, counselling and so on. But at root it is the same personal energy at work through these mediums that is present in sexual relations, family life, education, politics and religion in every sphere of life.

Two further points need to be made concerning the notion of ubuntu. The fulfilment of humanity aimed at and constituted by ubuntu is inseparably both individual and communal: the individual with $u b u n t u$ lives for others, the community with ubuntu lives for me. The more I find myself in the community, the more the community finds itself in me. This conception avoids the individualistic character of much European ethical thought as well as the collectivism of socialist and communist approaches that are usually reckoned the only alternatives. That is the first point. The second is more metaphysical.

It is customary in European thought to see morality as a cultural matter and not as the expression of a force of nature. In African thought there is no such division. The universe is seen as a field of force or energy in which humanity is immersed and part of. This field and the energy that constitutes it should not be thought of as either physical or psychic. African ontology is neither materialist nor dualist. The force or energy in question that is responsible for the simultaneous development of individual persons and the creation of community between them, has both physical and psychic aspects, but in itself is something more fundamental. It is for this reason that death is seen neither as the annihilation of a person nor as the liberation of an immaterial mind or soul.

Buhrmann has painted a vivid picture of how an ethic of ubuntu will show itself in health-care. It is a predominantly positive picture. And I, in my outline of the concept, have also stressed what I take to be the truth and value contained in it. Here however I must introduce a more critical note, first with regard to the concept of ubuntu itself, and then as regards health-care in the African tradition. 


\section{Critical Notes}

In South Africa the ethic of ubuntu is sometimes criticised for being too idealistic. Some of those who make this criticism are innocent - but stupid. What should an ethic be if not an ideal? The fact that Christians are not charitable, and Platonists, does not imply that there is something wrong with charity or justice. And, is it not far better for an ethic to consist in a system of ideals that indicate the direction to take for developing certain attitudes in persons than a system of rules determining behaviour? That conception of ethics has led to the widespread discrediting of ethics in contemporary culture.

Others who criticise the ethics of ubuntu in the name of realism are not so innocent. They are the 'practical' people - usually politicians or business leaders - who want to do away with ethics altogether. Their 'realism' is in reality self-interest, and differs with the differing selves.

A more important criticism is that the ethic of ubuntu has passed its sell-by date. It was at home in the rural village life of small communities. It is out of place in the world produced by European science and technology. There is some substance to this criticism. Cultures develop and so must their ethics. There is however no escaping an ethical judgment on these developments. And in making such a judgment on an ethical tradition one is engaging in its development. One cannot escape the absoluteness and universality of the ethical, however limited and particular the perspective from which one speaks. And I judge that there is much in the ethic of ubuntu that transcends the limitations of African culture. Presently I will try to show something of what that is.

When it comes to the sphere of health-care the inadequacies of the African tradition are fairly clear. It lacks the resources that European science and technology have made available to the medical profession. But, in addition to this lack there are elements in this tradition that are positively repugnant. They centre on the phenomenon of superstition, a superstitious recognition of evil forces wielded by human persons (witches for instance) and a superstitious reliance on evil practices (ritual murder for instance) to overcome these. There is sometimes also a superstitious fear of European medicine itself.

\section{A Health-care Ethic and the Complementarity of the Two Traditions}

I want to conclude this article by giving an indication of the complementarity of the two traditions by showing how they can be combined to provide a better 
foundation for a health-care ethic. This is just one example of a deeper complementarity that I think I discern, that is capable of providing a foundation for a truly human unity in the diversity of South Africa and even for an ethic for a multicultural world.

\section{Defining a Health-care Ethic}

As far as an ethics of health-care is concerned, I want to use as a foundation, the African emphasis on health as our flourishing as fulfilled human beings, and the inseparability of this flourishing from certain kinds of relationship with others. When it comes to a definition of what this flourishing consists in and thus of what it is to be a human being, I turn to European thought. I will use the idea of self-determination as the defining feature of our humanity and the criterion of its proper development and fulfilment. I thus hope to combine what is most characteristic of each tradition in a single theory of health-care. I do this, not out of any desire to achieve an apparent peace between two alien forces, but because I consider that both the conceptions I have mentioned are importantly true.

At once an apparent problem appears: is there not a simple contradicttion between the self-determination of the European tradition and the otherdependence of the African. How can these two insights be combined in a single view? I admit that the idea of having to rely on a certain influence of others in order to develop my capacity for free action is a paradoxical one. But I do not think it is contradictory, and will presently indicate why. In the meantime I will assume its truth and try to show how one can use it to build an ethical theory of health-care.

I define health in the most general normative sense as follows:

the total condition of persons whose capacities have developed to the point where they have the ability to engage in and enjoy the activities that promote their growth and express their fulfilment as persons.

Health, in this very general sense, thus includes all the dimensions of my being, everything that enables me to achieve personal growth and community with others. It must not however be thought that health in the narrow sense, namely 
that which is the concern of nurses and doctors and other health-care professionals, is the biological aspect of my life, simply as such. The proper sphere of health-care, narrowly considered, is indeed the impersonal, unconscious dimension of human life, but precisely insofar as it is capable of impeding or facilitating personal growth and community, the development of my capacity for self-determination in my relationships with others.

Thus from the point of view of the health-care ethics I am concerned to develop, what makes health-care professionals different from those in other professions, such as police, and teachers and ministers of religion, is not that they are concerned with the bodily aspects of persons rather than with personal growth and community as such (like those others), but that they are concerned with the bodily and impersonal aspects of human life insofar as these either facilitate or impede personal growth and community. Personal growth and community must remain their ultimate concern, even as health-care professionals. But they will serve this goal through focussing on the bodily and impersonal aspects of human life.

Having said that the main aim of health-care is personal growth and community I need to make clear that the cure and care of physical and psychic ailments is not simply a means to this end and hence of no importance in itself. Human persons are bodily beings, so bodily health is part of total health. Unlike playing tennis, or golf, for money, there is an intrinsic connection between curing and caring for the sick and promoting personal growth and community.

Because health-care, unlike education, focuses on the impersonal factors in human life, there is always a danger of losing the personal orientation that is central to an authentic ethic. One must remember always that the impersonal and the personal are both part of human nature and of the same human life. The attitude of the health-carer must reflect this. Health-care ethics, just as the whole of an ethics that is true to the ideal of ubuntu, must be based on human nature if it is to promote personal growth and community. This means that one cannot regard the human body as a merely physical system, a complex machine that is simply the instrument of a person who uses it. It is the physical aspect of a person. One's attitude to it is part of one's attitude to the person. Seeking to manipulate or dominate the natural physical processes that influence our lives as one might deal with a machine one had invented is bound to undermine the integrity of health-care. Medical science is the attempt to understand these processes. Health-care must put this understanding into practice by attempting to co-operate with and direct these processes to the 
fulfilment of the whole person. This goal, though is one that involves freely chosen acts, and is equally natural. Humanity and human fulfilment is not an artificial creation that can only be served by going against the dynamisms of nature. Medical science and technology must proceed within an attitude of reverence and respect for nature, even in its most material manifestations.

\section{Scientific Medicine and the Health-care Ethic}

There is a tendency for scientific medicine, because of its connection with a materialist world-view, to concentrate on the purely physical and chemical aspects of human nature rather than the psychic ones. But if the ultimate aim of humane health-care is to foster personal growth and community then the psychic factors in human life are in fact the more important. Psychologists and psychiatrists do in fact deal more directly with the proper goal of health-care. This is not to suggest that the psychic dimension in health be left to specialists. Rather it must be recognised that there is a psychic dimension to all health problems and to all health-care. This will be especially true of the work of general practitioners, but should be a feature of the specialisations as well.

In this connection we must remember that scientific knowledge, though real knowledge, is always only partial. It is partial, firstly, because it is always changing and usually increasing. But, more importantly, it will always be partial because there is that dimension of our personhood, science is unable to know at all, namely the capacity for thought and choice that makes science possible and judges its results. This dimension is also part of our nature. And although it transcends the observation- and measurement-based knowledge of science we nevertheless have real direct and personal knowledge of it, knowledge we can even make more or less critical and systematic in philosophy, but which is expressed and formulated in a looser way in all the major traditional systems of thought.

This personal and traditional knowledge is especially important for health-care if health-care is to be built on an attitude of reverence and respect for human nature. It is important both positively and negatively. It is important positively for the understanding of health it can provide beyond the reach of science. And it is important negatively because it reminds science of its partiality and ignorance and so encourages an attitude of humility on the part of scientific health-care. This lack of knowledge is especially clear in the case of our understanding of the beginning and the end of human life, of birth and 
death, but it is an element in our understanding of human life as such and as a whole.

\section{Ubuntu and the Health-care Ethic}

A health-care ethic that seeks to combine the best of both the European and the African ethical traditions must understand my health as my responsibility as well as that of the community. This is especially true if in fact, as we shall see, this responsibility can only emerge in the relationship between us. I, the patient, am the director and leader of the health-care team. But both of us, me and the team of health-care professionals are responsible for my personal growth and fulfilment and the growth of personal community between us. The ethic of ubuntu requires that health-carers are present to those they care for as persons and not simply as functionaries. They have to acquire moral virtues as well as technical skills. They must be committed to those whose health they care for. This in fact is contained in the meaning of the word 'profession'. It means 'vow'. This refers in the first place to the vow made by members of a religious community when they join a monastery or a convent. They take a vow of poverty, chastity and obedience. From then on they are considered 'professed' religious. At 'solemn profession' they take 'final vows', which means they are professed for life. Their aim is a complete commitment. Doctors also take a vow, the 'Hippocratic oath'. And this has a similar meaning, though a more restricted application. And just as professed religious, monks and nuns, are supposed to have a 'calling', a deep inner motivation, in order to sincerely take their vows, so too are those involved in health-care. It can't be 'just a job', a way of making a living, if it is to be an expression of ubuntu.

I am going to designate the fundamental interpersonal attitude required by ubuntu in health-care as that of 'care'. The quotation marks are intended to emphasize that I use this word in a definite and special sense. In this paper it means what I mean it to mean!

\section{The 'Care' Ethic}

The term 'care' denotes the appropriate personal relation of a person towards a person in need, whether that person be themselves or another. Because we are concerned with health needs we shall focus our analysis of care on this context. In general however the attitude of care is a form of interpersonal 
understanding and affirmation, where one of the persons in the relation is seen to be in a state of need of some kind. Unlike the fundamental interpersonal relation of persons that makes us persons, this relationship is thus asymmetrical: one is the carer, the other is the cared for. In what follows I shall assume, unless I say so, that the patient is cared for by others. Because, of course, patients care for themselves, and health-care workers care for each other and themselves. Or should!

Care is an attitude towards a person as a person, namely as a selfdetermining being. Thus recognition and respect for personal freedom is the moral foundation of health-care. We shall presently see that the effective exercise of one's freedom is dependent on one's empowerment by being known and affirmed by others. So this is a requirement as far as health-care workers are concerned: they must try to gain personal knowledge of their patients as individuals and find in their hearts some way of affirming them as the particular persons that they are. Only then will the patient's participation be characterised by effective freedom. This freedom can then be expressed by what could be called 'informed consent' to the caring relationship. The personal attitude of care will be the medium through which particular items of information and recommendations regarding medical procedures are conveyed so as to really reach and move the patient.

Care is not simply an attitude of a person to a person. Human persons are bodily and social beings. Care in the context of health-care entails the desire actually to do the person good as far as their health is concerned; it is beneficent. The health-care worker enters into relationship with the patient for that purpose, seeking to put themselves at their service to actually improve their health. Such a desire entails the desire to be competent and skillful in the diagnostic and technical aspects of health care. One desires intellectual skills, to know what is best to do. And one desires technical skills, the ability to do it. Care is not to be contrasted with competence.

The desire to promote health, as an ingredient of care, also involves a desire for justice in the distribution of health-care resources, both as regards patients and also for health-carers themselves.

\section{The 'Justice' Ethic}

Justice is the virtue of good relationships between persons, not with regard to the relationship itself, but with regard to the plurality of persons involved, even 
if only two. There must be some quality of proportion or order (fairness or equality) between persons in relation if the relation is to foster personal growth and community. And this is justice. Persons are of equal, because equally ultimate, value. And this must be reflected in their relationships.

In the world of scarcity, which is the whole of the impersonal and the social order, justice implies equal access to whatever resources there are. For the patient this means being treated on an equal footing with other potential or actual patients, either in general or in relation to a specific illness or medical resource. For the health-carer it means fair treatment regarding work-load and payment. A health-care service animated by the spirit of care as I have defined it would have justice as its guiding light.

Care thus regards the end of health-care, the fostering of personal growth through promoting health. Competence regards the means, which comprise both the science and the technology of medicine, aimed at the maintenance or restoration of the bodily and psychic integrity of the patient. Care is thus the foundation of health care, from which all else follows. It is a total attitude involving the intellect, the will and the emotions. Within it, one can distinguish certain subsidiary virtues of special importance for health-care.

\section{Subsidiary Values}

One such virtue could be called the 'rescue' virtue. This is the willingness to drop all else, including thought of one's own rights or safety, for the sake of the patient in an emergency situation. Obviously such a refusal to 'count the cost' (including the financial cost) must be balanced by a commitment to justice if it is to count as a virtue. But the preparedness for self-sacrifice it involves establishes it as a genuine aspect of ubuntu in health-care that can lift the whole sphere of health-care above the merely practical and utilitarian.

An opposite, but equally significant, virtue in health-care could be called 'medical modesty'. Because of the inherent threat in ill-health there is a temptation to make extravagant claims or promises concerning treatment, and to encourage false hopes. Health-care professionals occupy a position of immense power in their field and it is easy to misuse it. Medical modesty brings the health-carer down to the human level and establishes a deeper than merely professional solidarity with the patient. Medical modesty will also moderate the tendency - so very prevalent in commercial health-care - to over-treatment. 
The activity that most fully expresses the attitude of care is that which is the active service of the patient's health-care needs as a whole. The nurse is thus the definitive health-care professional. Other functions of a more specialised nature can be fulfilled by workers with more limited competence, but these will only serve the purpose of a humane health-care service to the extent that these workers are also skilled in the practice of nursing and animated by the virtue of care.

Actual health-care practice that approximates to this ethical ideal of health-care is that of the care associated with the modern hospice movement. At present, hospice medicine is limited to patients who are terminally ill, usually with some form of cancer. The hospice consists of a network constituted by the homes of the patients centred on a day-care clinic and hospital. The staff consists of a team of medical and other professionals including social workers and ministers of religion. This team 'services' the patients through regular contact in the patients' homes and at the day-care clinic and hospital. To call the hospice centre a clinic is perhaps a misnomer. It is an educational and social centre as well. Patients visit it for a variety of purposes, not only strictly medical ones. There is a library, a chapel, rooms for discussion and other group activity, a cafeteria, and, last but not least, hospital wards where patients stay for stabilisation treatment or, where home care is insufficient or impractical, to die in a milieu of total care.

I have said that hospice health-care is limited to terminally ill cases. It need not be. I see it in fact as a model for all health-care that takes every aspect of the person into account and sees health itself as one of the essential factors in the achievement of personal growth and community.

This concludes our outline of a health-care ethic in which the European and the African ethical traditions play complementary roles. As can be seen I have at times designated this ethic by the African term ubuntu in spite of the fact that I see the African and the European ethical insights as complementary. This is because I believe that the African insight that is the foundation of the ethic of ubuntu, namely that umuntu ngumuntu ngabantu, human beings depend on other human beings for the exercise, development and fulfilment of their human nature, remains true even when the essential feature of our humanity is seen as self-determination. As I have already said, this idea that we are dependent on others for our self-determination appears contradictory. I must now explain why I think that it is not. 


\section{Self-determination and Other-dependence}

In general it may be supposed that self-determination and other-dependence are opposed. This is certainly true of the physical realm: what is done by one thing or force is not done by another. In the personal sphere it seems otherwise. Two well-known examples suggest this: that of 'wild children' (children left to die at birth but growing to physical maturity quite outside all human society) and that of 'hospitalism' in babies in orphanages and other institutions. In both cases the absence of other persons, in the first case, and the absence of a caring relationship, in the second, quite prevented the development of those capacities regarded as defining our humanity - conceptual thought, responsible action, personal self-consciousness and self-determination.

These examples suggest the need for certain kinds of relationship with others if our natural capacities, in particular that for conscious selfdetermination, are to be developed. Phenomenological studies by many different authors go beyond mere suggestiveness and establish the truth of this beyond reasonable doubt. In fact such studies support an even stronger, even more paradoxical, conclusion: the more we are influenced by certain kinds of relationship with others the more self-determining we are enabled to be. Our freedom increases in direct rather than inverse relationship to their influence. We are literally empowered to be free.

I think reflection on our own experience can go some way to removing the sharpness of this paradox. Surely we have, all of us, had the experience of being empowered by others to do things we otherwise could not do. With some people, we say, we feel more able to be ourselves. And some of us, I think, have had the experience of affecting others in this way. Further reflection, of a philosophical kind, can, I think, remove the paradox of such inter-personal causality altogether.

If one examines the African conception of persons (that embodied in the saying umuntu ngumunttu ngabantu) more closely, one realises that the dependence on others involved is quite different from any scientific notion of causality. In fact to call the relationship creative of personal growth 'dependence' at all is misleading. One is led to this mistake by the common 'European' notion of a thing as a distinct and separate 'body'. Such bodies (or distinct 'atoms') are metaphysically primordial, and relations between them are secondary. For the African 'relational' view of persons, persons are 'present' in their relationships. Indeed one must think of persons as a complex 
of 'subsistent relations'. The relationship in which two persons meet each other is thus one of mutual 'transcendence'. Each is present to and in the other and only thus present to and in themself. If this sounds fanciful I recommend John Heron's fine essay 'The Gaze' (Heron 1970), in which he examines the phenomenon of perceiving the gaze of another, and in particular the experience of mutual gazing: me gazing at you gazing at me. It is the capacity that persons have of transcending their own limitations by becoming present to the thoughts and feelings of another, and also by revealing their own innermost thoughts and feelings to the other, of a real self-transcendence and self-donation, that is the essence of the African conception.

These features of the intersubjective relations of persons reveal a dimension of human nature that transcends the field of scientific investigation and is incompatible with physicalism or any materialist metaphysics. But it is not dualistic either. For the relational view, the strictly personal unity of a human individual subsists through a duality of relationships, a relationship to oneself that consists in self-consciousness and self-determination, and a relationship to what is other than oneself that consists in self-transcendence and self-donation. And the relationship to self is only possible through the relationship to the other, and vice versa. Both relations are equally primordial. As a consequence, genuine freedom of the individual cannot be understood as sheer independence. Nor can authentic human community exist without the interdependence of free persons.

\section{Conclusion}

I hope I have done enough in this essay to show how the co-reflection of different cultures on a common practice such as health-care can unearth values that are genuinely complementary because rooted in our common human nature, and that, because of this, the values discovered have a scope beyond that of the particular practice concerned. I have suggested a reason for this, namely a certain limitlessness of our human nature such that no single perspective can exhaust its possibilities. It follows from this that an ongoing conversation between the different cultures and thought-systems of the world is essential if we are to discern in the different spheres of life values that are genuine and genuinely complementary because rooted in our common human nature and so productive of an authentic human coexistence. 
I do however wish to make a further, and final, point. It concerns the importance of the African relational view of human nature and the ethic of ubuntu it makes possible. It is my view that this ethic, and this alone, provides a framework for authentic human community in a pluralistic world. The African idea that one can only realise oneself, discover one's true identity, in the other, embodies a spirit that is essential for the intercultural co-reflection I have spoken of above. This spirit of openness to the alien, of readiness to assimilate what is foreign, of creative synergy, is typical of Africa. From an economic or political point of view Africa often appears as a kind of 'black hole' in the contemporary international cosmos. Culturally however, it is otherwise. Throughout the twentieth century European culture in its present impoverished form has been taking over the world. Wherever it has gone it has obliterated local cultures one after the other: the Inca culture in South America, that of the First Nation people in the North, Aboriginal culture in Australia, the Maori in New Zealand. No other culture seems able to resist its inexorable advance. In Africa however, to some extent, this has not happened. Indigenous knowledge systems seem to be holding their own. This is certainly the opinion of Tony Balcomb, the scholar to whom I have already referred. He writes as follows:

In Africa it is everywhere - existing alongside, in, or in opposition to, modern forms of knowledge. Westernization, or modernity, has, in many ways, met its match in Africa.

And he concludes that 'one of the reasons for this is perhaps to do with the African way of dealing with the different, the Other, the alien'.

I think he is right. It is the spirit of ubuntu. I think it is what we need in South Africa in order to build our rainbow nation. I think it is what we all need, to achieve solidarity in a post-modern world.

\section{References}

Balcomb, A. 2005. The Ethos Indigenous Knowledge Project. (Unpublished MS.)

Buhrmann, V. 1984. Living in Two Worlds. Cape Town: Human and Rousseau. Felhaber, T. (ed.) 1999. South African Primary Health Care Handbook. Cape 
Town: Copy Cat Communications.

Heron, J. 1970. The Phenomenology of Social Encounter: The Gaze.

Philosophy and Phenomenological Research 10: 243 - 264.

MacIntyre, A. 1985. After Virtue. London: Routledge.

McCabe, H. 1980. How to be Happy. (Unpublished MS.)

Taylor, C. 1989. Sources of the Self. Cambridge: Harvard University Press.

Augustine Shutte

Department of Philosophy University of Cape Town lara.davison@uct.ac.za 